
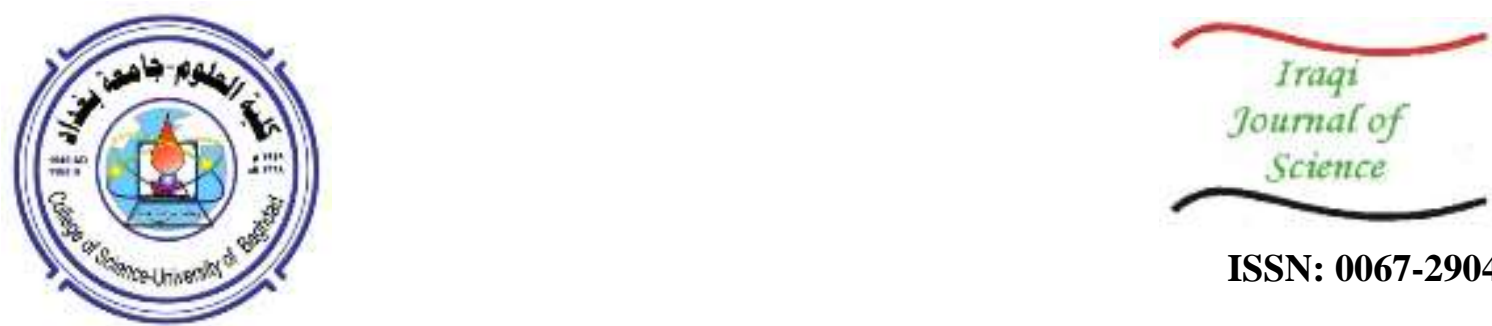

ISSN: 0067-2904

\title{
Electroluminescence of Light- Emitting Organic Semiconductor / Europium Oxide Nanoparticle Hybrid Junction
}

\author{
Hussein Riyadh Mohammed*, Omar A. Ibrahim \\ Department of Physics, College of Science, University of Baghdad, Baghdad, Iraq
}

Received: 22/7/2019 Accepted: 19/11/2019

\begin{abstract}
A hybrid nanoparticles light emitting diode (NPs-LED) was fabricated as layers of ITO/TPD:PMMA/ $\mathrm{Eu}_{2} \mathrm{O}_{3} / \mathrm{Alq}_{3} / \mathrm{Al}$, by phase segregation method using spin coating technique. The NPs-LED hybrid device emitted light and consisted of three layers in a definite order placed on the transparent conducting oxide as an ITO substrate; the first layer was made of (N, N'-bis (3-methylphenyl) -N, N'-bis (phenyl) benzidine) (TPD) and polymethyl methacrylate (PMMA) polymers combined together. The second layer consisted of Europium (III) oxide $\left(\mathrm{Eu}_{2} \mathrm{O}_{3}\right)$, while the third layer was $\mathrm{Alq}_{3}$, one of the most frequently-used electron transport layers.

The electroluminescence (EL) of NPs-LED was studied with different bias voltages $(20,25$ and 30V) at room temperature. Depending on the CIE 1931 color spaces, $\mathrm{X}$ the white light was generated at $30 \mathrm{~V}$ and the green light at $20 \mathrm{~V}$. This was achieved by benefitting from the transition between deep levels in the energy gap of $\mathrm{Eu}_{2} \mathrm{O}_{3}$ NPs (surface state) and magnetic dipole transition for $\operatorname{Eu}^{+}\left({ }^{5} \mathrm{D}_{0-3}\right.$ and ${ }^{5} \mathrm{~L}_{6}$ to $\left.{ }^{7} \mathrm{~F}_{0-6}\right)$. The Current - Voltage (I-V) characteristics demonstrated that the current varies with voltage and that the knee voltage value is $5 \mathrm{~V}$. The EL spectrum showed a broad band emission, with a range of $350-700 \mathrm{~nm}$. Finally, the correlated color temperature (CCT) was found to be about 7100 to $11500 \mathrm{k}$.
\end{abstract}

Keywords: Europium oxide, Nanoparticle, electroluminescence, light-emitting diode

\section{الاضائية الكهربائية لضوء المنبعث من شبه الموصل /دقائق اوكسيد اليوربييوم النانوي لمفرق هجين

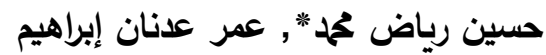

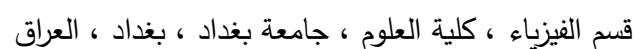

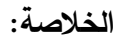

ITO / TPD: تمنيع الصمام الثنائي الباعث للجسيمات النانوية (NPs-LED) كطبقات من التهات

PMMA / Eu2O3 / Alq3 / Al

الدوران. يتكون الجهاز الهجين NPs-LED الذي ينبعث منه الضوء ، من ثلاث طبقات بترتيب محدد يوضع

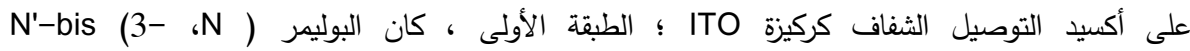

polymethyl والبوليمرات (N'-bis (phenyl) benzidine) (TPD ،methylphenyl) -N

Europium ممزوجين مع بعضهما, تمزج معهما الجزيئات النانوية من أكسيد (methacrylate (PMMA

(Eu2O3) (III) ، بينما كانت الطبقة الثالثة هي Alq3 كأحد وسائل النقل الإكترونية الأكثر استخدامًا. 


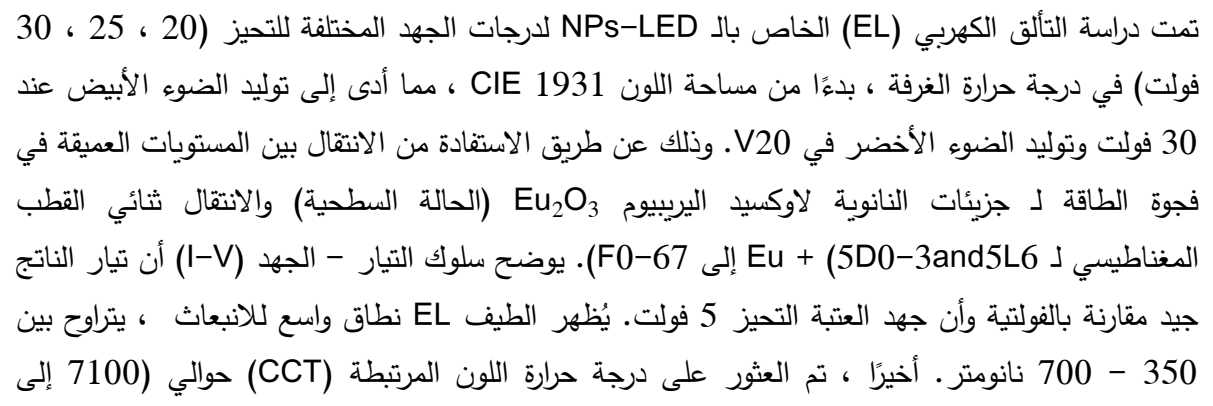

\section{Introduction}

Europium (III) Oxide $\left(\mathrm{Eu}_{2} \mathrm{O}_{3}\right)$ is a synthetic compound made up of europium and oxygen. It is generally utilized as a red or blue luminescent substance in TVs and fluorescent lights because of its wide band gap for bulk (3.7eV) [1]. The deep sub levels ( ${ }^{5} \mathrm{D}_{0} \rightarrow{ }^{7} \mathrm{~F}_{0,1,2,3}$ and 4 ) in $\mathrm{Eu}_{2} \mathrm{O}_{3}$ are resulting from the splitting of spectrum lines, which is known as the effect of stark on the atom. It can also partially occur because of the presence under the influence of an external electric field, which can be responsible for the emission of a band with different colors that include the whole visible spectrum [2, 3]. Due to this property, $\mathrm{Eu}_{2} \mathrm{O}_{3}$ is used in white LEDs [4]. The blend of nanoparticles of europium oxide (n-type) with some organic and inorganic semiconductors (p-type) will produce unique electronic and optical properties of the manufactured heterostructure device [5].

The result of the integration of semiconductor nanoparticles into organic matrices is the formation of a pn junction (EL device). Platting dielectric nanoparticles in an organic light-emitting hybrid junction affects the luminescence spectra, since the energy levels of the lowest unoccupied molecular orbital (LUMO) and the highest occupied molecular orbital (HOMO) of the TPD polymer are close to the energy level of the embedded semiconductor. Therefore, energy transfer will occur, as well as electronic polarization of the environment. If dielectric inclusions have a stronger polarization than the polymer matrix, the EL spectrum of the dielectric / polymer hybrid film will have red shifts compared with the fluorescence of the same dielectric material [6]. In this work, $\mathrm{Eu}_{2} \mathrm{O}_{3}$ NPs were used to make a TPD: PMMA: $\mathrm{Eu}_{2} \mathrm{O}_{3}$ NP hybrid coupler using spin coating and their EL and PL properties were studied. The light-emitting layers of the $\mathrm{Eu}_{2} \mathrm{O}_{3}$ NPs were obtained using the phase segregation method. This method is an inexpensive and simple solution process without using sophisticated vacuum equipment to manufacture a device based on $\mathrm{Eu}_{2} \mathrm{O}_{3}$ [1]

\section{Experimental Work}

For the preparation of hybrid films made of organic and inorganic materials, a transparent glass plate of indium oxide and tin (ITO) was used as the basis on which the layers of the thin films are located. The N, N'- diphenyl-N, N'- bis (3-methylphenyl) - 1,1'- biphenyl-4,4'- diamine (TPD) solution was prepared by dissolving $70 \mathrm{mg}$ of the TPD in $1 \mathrm{ml}$ chloroform. Likewise, a solution of PMMA in chloroform was prepared in a proportion of $3 \mathrm{~g}: 100 \mathrm{ml}$. . The two solutions of TPD and PMMA were mixed to prepare a blend with NPs in a ratio of 1: $0.5 \% . \mathrm{Eu}_{2} \mathrm{O}_{3}$ was added at a percentage of $\mathrm{X} / 200$ or $\mathrm{X} * 0.005$ to the blend of TPD:PMMA. The mixture of blend and NPs was prepared by a magnetic stirrer and an ultrasound path, after that the film was prepared. We used a clean ITO, on which the mixture (blend and $\mathrm{Eu}_{2} \mathrm{O}_{3}$ ) was deposited by spin-coating at $2500 \mathrm{rpm}$ for 30 seconds. This was followed by drying by oven at $70^{\circ} \mathrm{C}$ for 2 hours to obtain the first layer of the device. In the same time, Tris (8-hydroxyquinolinato) aluminum $\left(\mathrm{Alq}_{3}\right)$ (electron injection layer) was dissolved in ethanol (insoluble solvent of TPD) at a ration of $70 \mathrm{mg}: 3 \mathrm{ml}$. In the same way, this layer was deposited on the first layer by spin-coating at $2500 \mathrm{rpm}$ for 30 seconds. Then the films were placed in oven at $60^{\circ} \mathrm{C}$ for 2 hours to eliminate the remaining solvents . Finally, aluminum contact was deposited by thermal evaporation under $4 * 10^{-5}$ mbar pressure as a negative cathode to obtain the (ITO/TPD: PMMA/ $\mathrm{Eu}_{2} \mathrm{O}_{3} / \mathrm{Alq}_{3} / \mathrm{Al}$ ) device . 


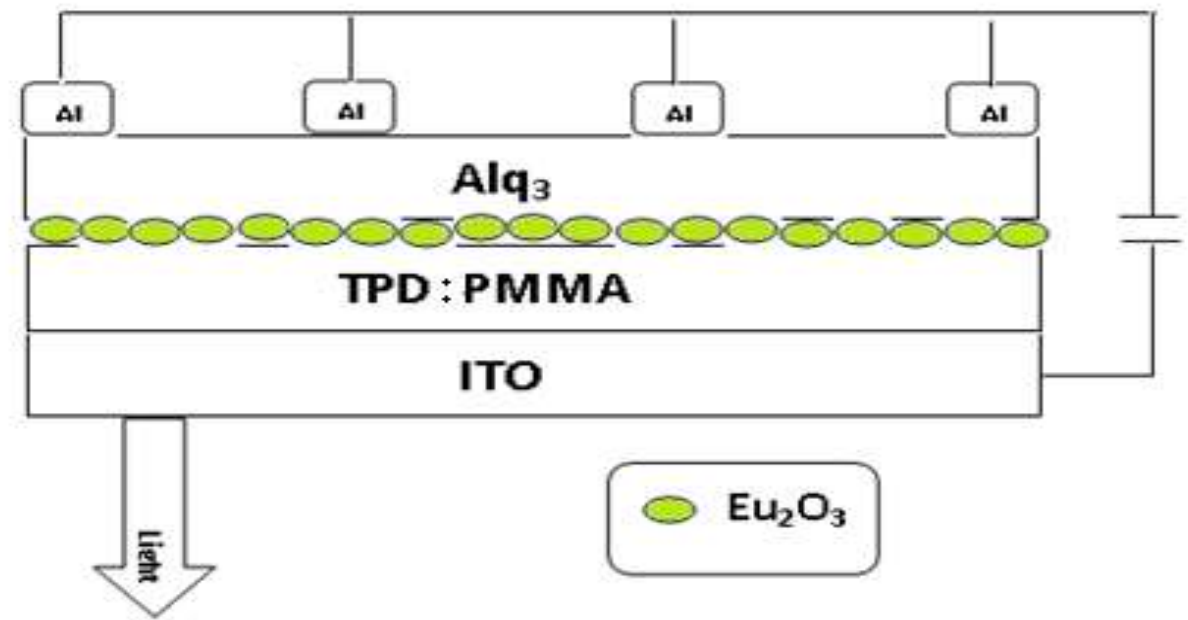

Figure 1-Structure of hybrid junction devices using $\mathrm{Eu}_{2} \mathrm{O}_{3} \mathrm{NP}_{\mathrm{S}}$

Figure-1 demonstrates the structure of the hybrid junction (TPD:PMMA/ $\mathrm{Eu}_{2} \mathrm{O}_{3}$ NPs) device prepared by the phase segregation of $\mathrm{Eu}_{2} \mathrm{O}_{3}$ nanoparticles on the organic blend layer. The structure of the device is comprised of three layers kept progressively on the base layer of ITO by phase segregation through utilizing the spin-coating technique. Indium tin oxide (ITO) is the most generally utilized option to incorporate other straightforward conductive oxides. The natural layer comprised of the TPD is a hole transport film, while the Eu2O3 NPs and $\mathrm{Alq}_{3}$ films form the electron transport layer. The phase segregation method was used because the viscosity of NPs in chloroform is different from that of the blend (TPD: PMMA), which leads to separating them through the spin-coating. To investigate the electrical properties of the hybrid junction device, Hall Effect measurements were conducted by HMS-3000 and I-V characteristics were studied to assess the EL device by a Keithley 616 advanced electrometer and a DC source. The EL range of the EL device was estimated at room temperature by a fiber-optic spectrometer of the CCS arrangement (thorlabs, Germany) in the inclusion scope of $200-1000 \mathrm{~nm}$ and targets of $1 \mathrm{~nm}$.

\section{X-Ray Diffraction Results for $\mathrm{Eu}_{2} \mathrm{O}_{3} \mathrm{NPs}$}

The crystal graphic orientation of $\mathrm{Eu}_{2} \mathrm{O}_{3} \mathrm{NPs}$ was studied by X-ray diffraction patterns recorded at a scanning range $(2 \theta)$ of $5^{\circ}-80^{\circ}$, as shown in Figure-2. The X-ray diffraction patterns included many diffraction peaks. The high intensity of the orientation peak was at $2 \theta=27.1865^{\circ}$ which is diffracted from miller indices (222), while the crystal structure used was wurtzite. There were no crystalline defects in the X-ray . From the linear fit of the data, the crystal size (d) was found to be $40.2 \mathrm{~nm}$ ).

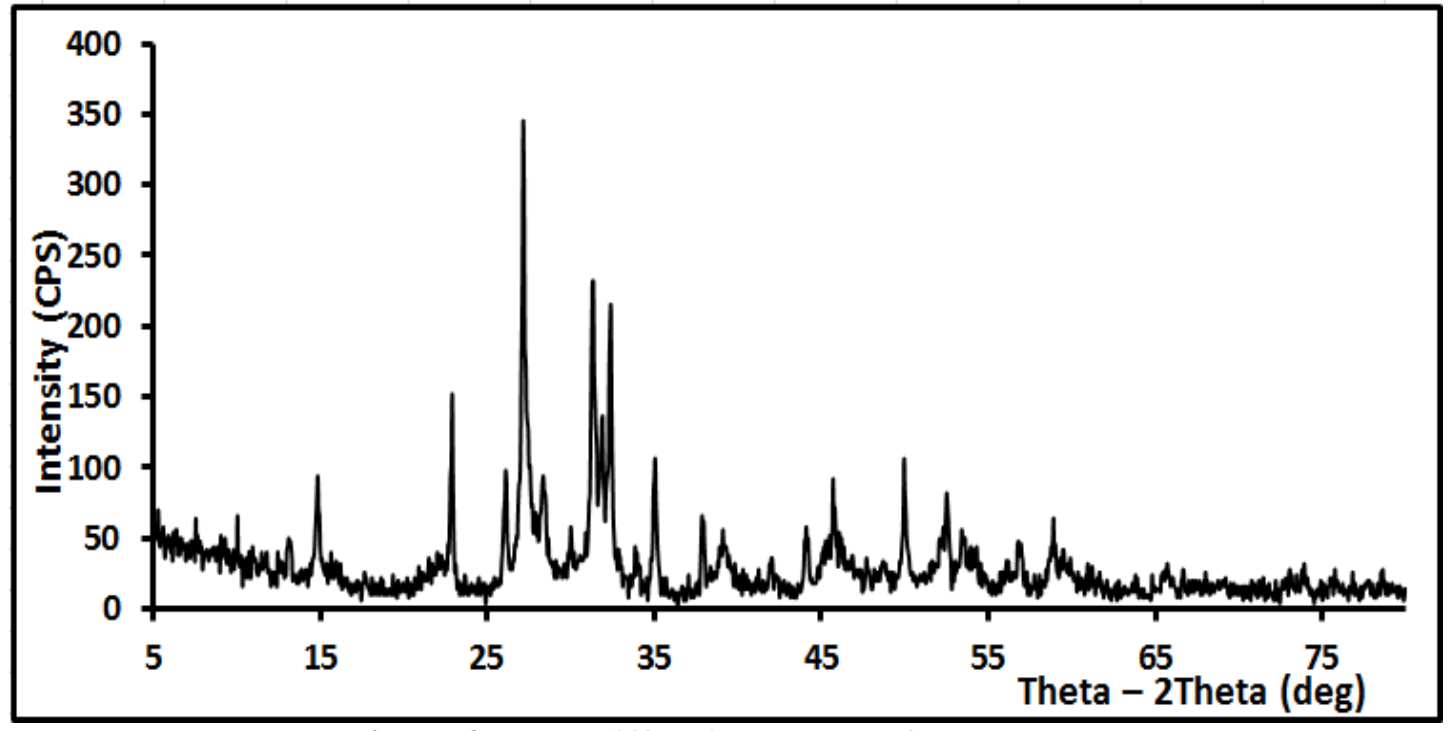

Figure 2-X-ray diffraction pattern of $\mathrm{Eu}_{2} \mathrm{O}_{3} \mathrm{NPs}$. 


\section{Electrical Measurements}

The Hall Effect system type (Ecopia HMS -300) was used to study the electrical properties of $\mathrm{Eu}_{2} \mathrm{O}_{3}$, for which the results are outlined in Table-1. The film of $1 \mu \mathrm{m}$ density indicates a semiconductor of $\mathrm{n}$ - type conductivity. Table-1, shows the results of conductivity and Hall Effect parameters of the $\mathrm{Eu}_{2} \mathrm{O}_{3}$ NPs that was deposited by drop casting on a glass substrate etched by HF solution.

Table 1-Conductivity and Hall measurements of the $\mathrm{Eu}_{2} \mathrm{O}_{3}$ NPs

\begin{tabular}{|c|c|c|c|c|c|}
\hline sample & $\begin{array}{c}\text { Conductivity } \\
(\Omega . c m)^{-1}\end{array}$ & $\begin{array}{c}\text { Mobility } \\
\left(\mathrm{cm}^{2} / \mathrm{V} . \mathrm{s}\right)\end{array}$ & $\begin{array}{c}\text { Bulk } \\
\text { Concentration } \\
\left(\mathrm{cm}^{3}\right)\end{array}$ & $\begin{array}{c}\text { Hall } \\
\text { Coefficient } \\
\left(\mathrm{m}^{2} / \mathrm{C}\right)\end{array}$ & $\begin{array}{c}\text { Resistivity } \\
(\Omega . c m)\end{array}$ \\
\hline $\mathrm{Eu}_{2} \mathrm{O}_{3}$ & $1.584 \mathrm{E}-4$ & $6.292 \mathrm{E}+2$ & $-1.571 \mathrm{E}+12$ & $1.584 \mathrm{E}-4$ & $6.315 \mathrm{E}+3$ \\
\hline
\end{tabular}

The Current-Voltage (I-V) characteristics of the hybrid junction ITO/TPD: PMMA/ $\mathrm{Eu}_{2} \mathrm{O}_{3} / \mathrm{Alq}_{3} / \mathrm{Al}$ device, as the ability of the predisposition voltage at room temperature, is presented in Figure-3.

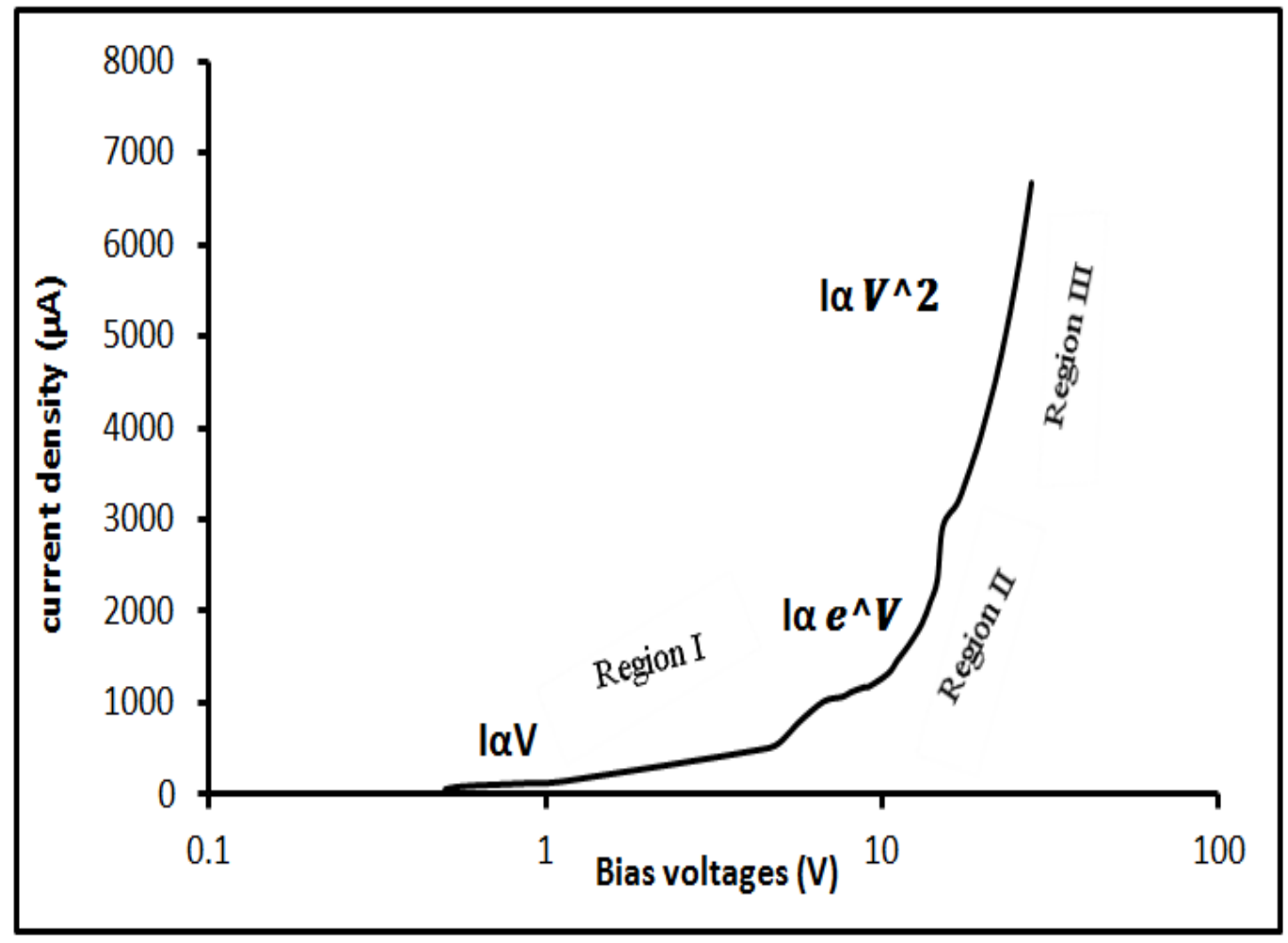

Figure 3-Semi- log plot of the current-voltage (I-V) characteristics for ITO/TPD: PMMA/ $\mathrm{Eu}_{2} \mathrm{O}_{3} / \mathrm{Alq}_{3} / \mathrm{Al}$ hybrid junction device.

The resulting I-V characteristics of the ITO/TPD: PMMA/ $\mathrm{Eu}_{2} \mathrm{O}_{3} / \mathrm{Alq}_{3} / \mathrm{Al}$ hybrid junction device were analyzed using the standard thermionic emission theory [7]. The results illustrate that the current transport mechanism was exhibited in three different regions. The current density in region (I) $(<5 \mathrm{~V})$ pursues a direct linear relationship (Ohmic relationship) $(\mathrm{I} \alpha \mathrm{V})$. This indicates that the current transport is dominated by tunneling at low voltages [8]. The boundary for this area was determined below the knee tension $(5 \mathrm{~V})$.

In region (II) $(5-20 \mathrm{~V})$, the current density increased exponentially as (I $\alpha$ exp (V)) carriers are injected into the dielectric are produced because of a thermionic procedure coursing through the hindrance. Thus, the number of the free charges was less than the ratio of the trapped charges. The results also demonstrated the exponential voltage dependence [8]; with further utilization of voltage, 
the injected carriers quickly increase, and the traps are filled (the traps states are ${ }^{5} \mathrm{D}_{0},{ }^{5} \mathrm{D}_{1},{ }^{5} \mathrm{D}_{2},{ }^{5} \mathrm{D}_{3},{ }^{5} \mathrm{~L}_{6}$ ,NPs state and defect stated) [2] at 20V which is called Traps-Filled-Limit Voltage (VTFL).

Above $20 \mathrm{~V}$ (region III), the current density obeys the power law $\left(\mathrm{I} \alpha \mathrm{V}^{2}\right)$. The light discharge starts at region (III), in $20 \mathrm{~V}$ and $610 \mu \mathrm{A}$, in light of the fact that the transport through the ITO/TPD: PMMA/ $\mathrm{Eu}_{2} \mathrm{O}_{3} / \mathrm{Alq}_{3} / \mathrm{Al}$ The hybrid layer is driven by Trap-Charge Limited Current ( TCLC) in the hole of the $\mathrm{Eu}_{2} \mathrm{O}_{3}$ NPs. This infers that the density of the injected charge carriers is significantly important as compared to the thermally delivered free charge carriers. Space-Charge Limited Current (SCLC) is the dominant charge carrier transport [9].

The I-V characteristics of the three samples show an exponential increase in current due to the decrease in the depletion layer width at the interface. Under the forward bias, the conduction band barrier will be decreased due to the exponential distribution of electrons and holes within the conduction and valence bands. Hence, the diffusion current flows across the junction increases exponentially with increasing the forward bias. The drift current flowing in the opposite direction does not depend on the potential barrier height and will enhance the electron flow from the n-( NPs) to the $\mathrm{p}$-(TPD) and that of the holes from the p-(TPD) to the $\mathrm{n}$-( NPs). The successive recombination would give rise to the forward bias current flow. This means that the diode resistance would firstly decrease upon the increase of the forward bias voltage (i.e., the lowering of the barrier). The semi-log plot of the I-V data at RT is shown in Figure- 3 and it illustrates that the current transport mechanism is exhibited in three different regions.

\section{Electroluminesces Measurements}

Electroluminescence estimations at forward bias voltages of $25 \mathrm{~V}$ speak to possible for the light which has been acquired tentatively through the hybrid device. Hybrid junction devices were carried out using a photomultiplier detector at room temperature. The transport component of the carrier in this hybrid coupling device performs so that the TPD works as a hole transport layer and $\mathrm{Alq}_{3}$ as an electron transport layer. The gaps are brought by the ITO anode in the HOMO of the terminal potential difference grid. It is then shipped to the VB or to ${ }^{7} \mathrm{~F}_{0},{ }^{7} \mathrm{~F}_{1-2},{ }^{7} \mathrm{~F}_{3-4}$, and ${ }^{7} \mathrm{~F}_{5-6}$ of the Charge Transfer (CT) of $\mathrm{Eu}_{2} \mathrm{O}_{3}$. In the meantime, electrons are injected at the cathode into the Alq3 LOMO networks and moved to the conduction band (CB) or to ${ }^{5} \mathrm{D}_{0},{ }^{5} \mathrm{D}_{1},{ }^{5} \mathrm{D}_{2},{ }^{5} \mathrm{D}_{3}$, and ${ }^{5} \mathrm{~L}_{6}$. The condition of the CT and the demonstrated imperfection of the $\mathrm{CT}$ of $\mathrm{Eu}_{2} \mathrm{O}_{3}$ [2] are presented in Figure-5. Subsequently, holes and electrons in $\mathrm{Eu}_{2} \mathrm{O}_{3}$ NPs are also recombined as excisions, also known as inter band recombination. This recombination process of holes and electrons through the deformities leads to produce a light at various wavelengths. The process that involves the recombination by imperfections is called Shockley-Reed-Hall recombination [10, 11].

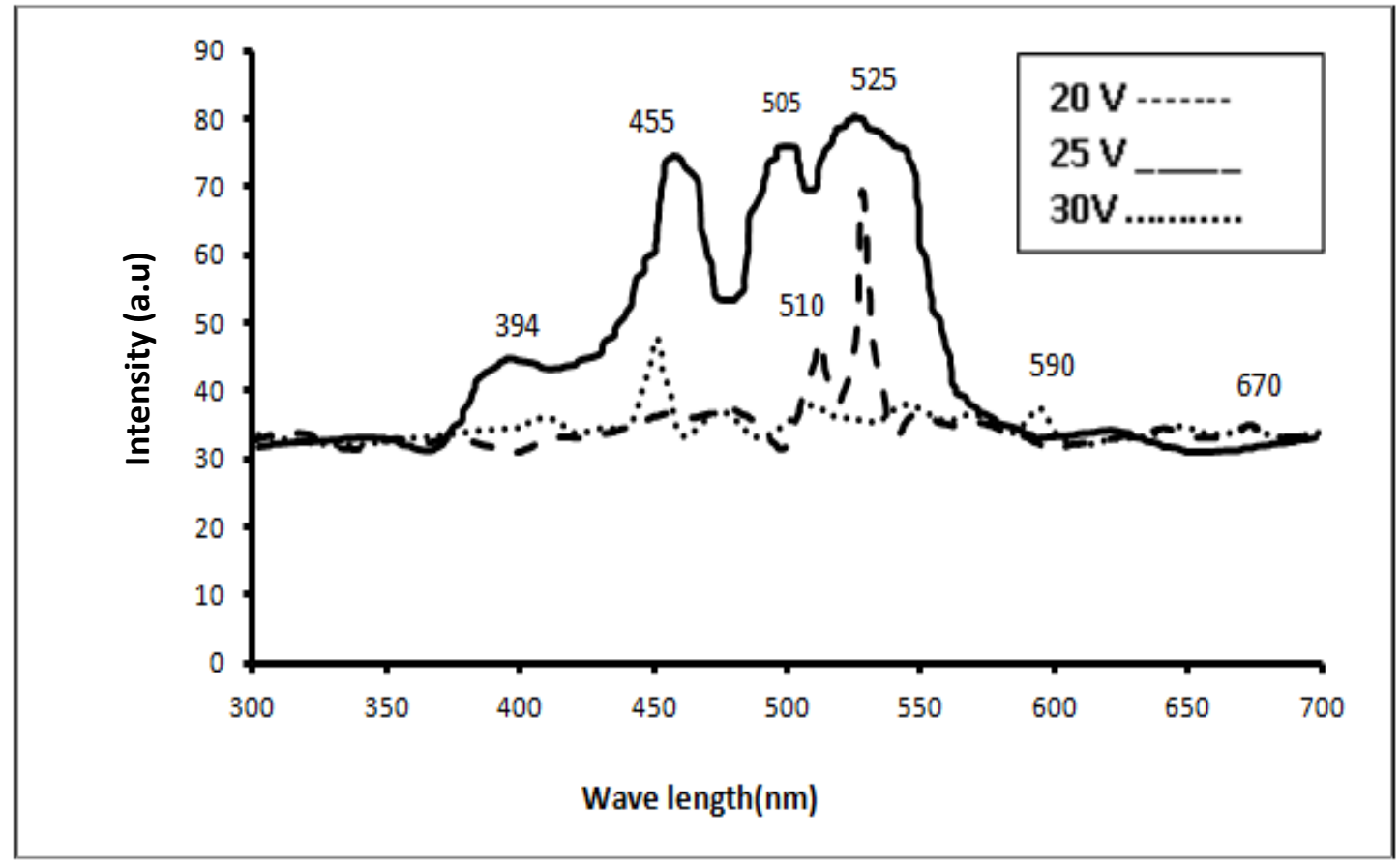

Figure 4-EL of TPD:PMMA/Eu $\mathrm{O}_{3} / \mathrm{Alq}_{3}$ at different voltages. 


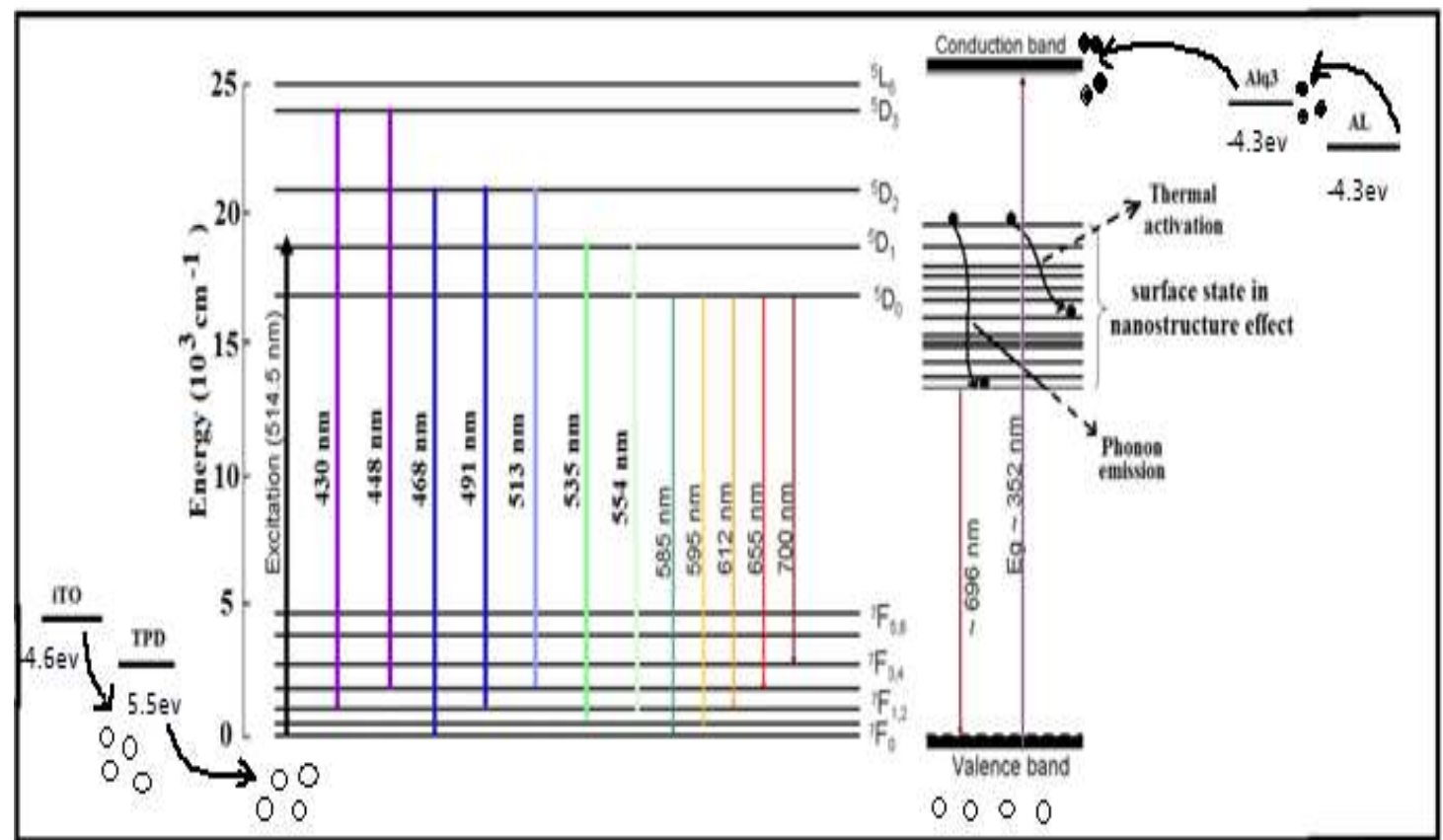

Figure 5-Energy bands diagram of ITO/TPD: $\mathrm{PMMA} / \mathrm{Eu}_{2} \mathrm{O}_{3} / \mathrm{Alq}_{3} / \mathrm{Al}$ hybrid device [2,3, 13and 14].

The violet radiation at $\approx 360 \mathrm{~nm}$ is caused by the band to band transition [2]. The transition from the blue emission of $430 \mathrm{~nm}$ to blue emission of $513 \mathrm{~nm}$ corresponds to the transitions of ${ }^{5} \mathrm{D}_{3}$ and ${ }^{5} \mathrm{D}_{2}$ to ${ }^{7} \mathrm{~F}_{0},{ }^{7} \mathrm{~F}_{2}$ and ${ }^{7} \mathrm{~F}_{3}$. This result is in a god agreement with Yoshimoto et al. [12]. The EL peak at $410 \mathrm{~nm}$ is corresponding to the emission of TPD because the energy of these peaks is equal to the band gap of TPD $3 \mathrm{eV}$ [6]. The peak at 410nm appeared when utilizing NPs of Europium oxide, where vitality utilizing Auger is expected to nanoscale substances that cause a high Auger recombination cross area. With an abatement in TPD, the number of injected holes through the interface NP TPD/ $\mathrm{Eu}_{2} \mathrm{O}_{3}$ is diminished. Electrons are productively injected into the conduction band of $\mathrm{Eu}_{2} \mathrm{O}_{3}$ NPs $[13,14]$.

Excitations through nan-radiative vitality move from the TPD to the Eu2O3 NPs because the EL device structures with a sub-10nm separation between TPD and Eu2O3 NPs [15]. The green emission 513- 585nm corresponds to ${ }^{5} \mathrm{D}_{0},{ }^{5} \mathrm{D}_{1}$ and ${ }^{5} \mathrm{D}_{2}$ to ${ }^{7} \mathrm{~F}_{0},{ }^{7} \mathrm{~F}_{1-2}$ and ${ }^{7} \mathrm{~F}_{3}$ transitions $[2,12]$. The orange $595 \mathrm{~nm}$ to red emission around $700 \mathrm{~nm}$ is related to ${ }^{5} \mathrm{D}_{0}$ to ${ }^{7} \mathrm{~F}_{0},{ }^{7} \mathrm{~F}_{1-2}$ and ${ }^{7} \mathrm{~F}_{3-4}$ transitions or to the nan-radiative vitality of the surface state in nanostructure to V.B of $\mathrm{Eu}_{2} \mathrm{O}_{3}$ [3]. All of these advances are shown in Figure-5). The shade of light is situated by the color spaces CIE 1931 Chromaticity Coordinate (Figure- 6) . It implies that the $\mathrm{x}$ and $\mathrm{y}$ are obtained with the help of X Y \& Z.

$$
\begin{gathered}
x=\frac{X}{X+Y+Z} \\
y=\frac{Y}{X+Y+Z}
\end{gathered}
$$

where all the three coordinates are zone underneath bend for red, green and blue are districts in EL range, separately. The correlated color temperature(CCT) can be calculated with the help of McCamy's formula. The correlated color temperature with the use of $\mathrm{x}$ and $\mathrm{y}$ chromaticity is calculated as in Eq. 3 [13]:

$$
C C T=-449 n^{3}+3525 n^{2}-6823 n+5520.33-
$$

where $\mathrm{n}$ equals to,

$\boldsymbol{n}=(\boldsymbol{x}-\mathbf{0 . 3 3 2}) /(\boldsymbol{y}-\mathbf{0 . 1 8 5 5})$

Table-2, shows the values of $\mathrm{x}, \mathrm{y}$ and CCT. 
Table 2-CCT and $\mathrm{x}$, y coordinates for different bias voltages.

\begin{tabular}{|c|c|c|c|}
\hline Simple & Bias voltage & $\mathrm{x}, \mathrm{y}$ & $\mathrm{CCT}(\mathrm{K})$ \\
\hline \multirow{2}{*}{$\begin{array}{c}\text { ITO/TPD: PMMA/0.5\%w } \\
\mathrm{Eu}_{2} \mathrm{O}_{3} / \mathrm{Alq}_{3} / \mathrm{Al}\end{array}$} & 20 & $0.3,0.327$ & $7213 \mathrm{~K}$ \\
\cline { 2 - 4 } & 25 & $0.168,0.43$ & $11416 \mathrm{~K}$ \\
\cline { 2 - 4 } & 30 & $0.306,0.29$ & $7718 \mathrm{~K}$ \\
\hline
\end{tabular}

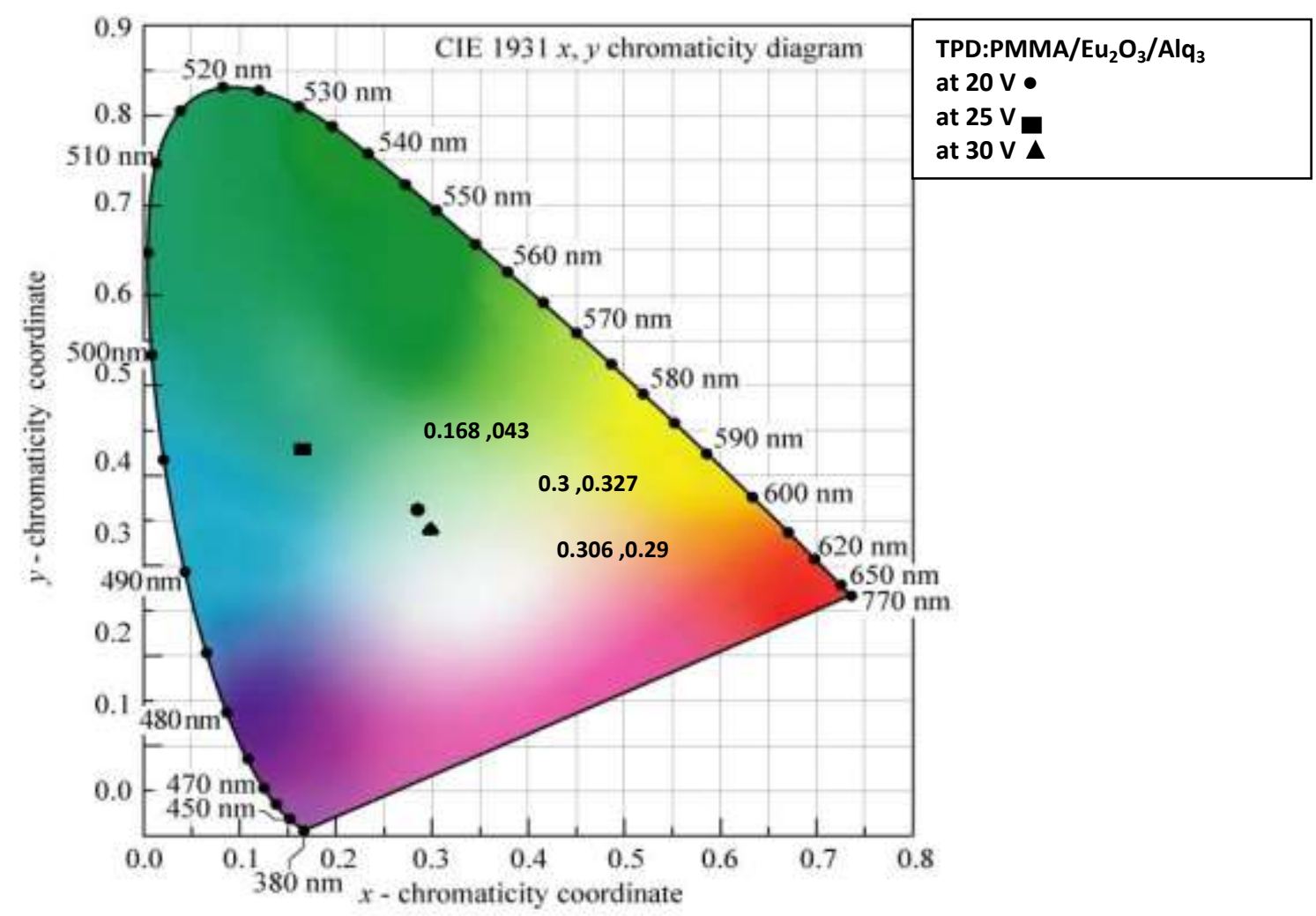

Figure 6-CIE 1931 chromaticity diagram for ITO/TPD: PMMA/ Eu2O3/Alq3/Al hybrid junction device.

\section{Conclusions}

As a summary of the results, we demonstrated that organic - inorganic hybrid composites emit green and white light emission by controlling the bias voltage from the transition through the deep levels in energy gap of $\mathrm{Eu}_{2} \mathrm{O}_{3} \mathrm{NPs}\left(5 \mathrm{D}_{0-3}\right.$ and $5 \mathrm{~L}_{6}$ to $\left.7 \mathrm{~F}_{0-6}\right)$ and through the defect states of these NPs. White light generation is attributed to the increased number of transitions through the deep levels of $\mathrm{Eu}_{2} \mathrm{O}_{3}$ by increasing the bias voltage. The bandwidth of the EL of the hybrid film spans as wide as $250 \mathrm{~nm}$. The white light emission is attributed to the interaction of the organic and inorganic components of the hybrid film.

\section{References}

1. Yuen Y., Chun-Yu L., and Ching-Fuh L. 2007. White Light Electroluminescence from Europium Oxide Nanocrystal/Organic Composites. Conference IEEE, Hong Kong, Hong Kong.

2. Lourenco, S.A., Dantas, N.O., Serqueira , E.O., Ayta , W.E.F., Andrade, A.A., Filadelpho , M.C., Sampaio ,J.A., Bell, M.J.V. and M.A. Pereira-da-Silva, M.A. 2011." $\mathrm{Eu}^{3+}$ photoluminescence enhancement due to thermal energy transfer in $\mathrm{Eu}_{2} \mathrm{O}_{3}$-doped $\mathrm{SiO}_{2}-\mathrm{B}_{2} \mathrm{O}_{3}-\mathrm{PbO}_{2}$ glasses system" Journal of Luminescence, 131: 850-855

3. Suhail, A.M., Khalifa, M.J., Saeed, N.M. and Omar. A. 2010. "White light generation from CdS nanoparticles illuminated by UV-LED" Eur. Phys. J. Appl. Phys. 49: 30601.

4. Wakefield, G., Keron, H.A., Dobson, P.J. and Hutchison, J.L. 1999. Synthesis and Properties of Sub-50-nm Europium Oxide Nanoparticles. Journal of Colloid and Interface Science, 215(1): 179182 
5. Xue Yin, Shenwei Wang, Guangyao Mu, Guangmiao Wan, Miaoling Huang and Lixin Yi. 2017. Observation of red electroluminescence from an Eu2O3/p+-Si device and improved performance by introducing a Tb2O3 layer. Journal of Physics D: Applied Physics, 50(10).

6. Litvin, A. P., I. V. Martynenko, F. Purcell-Milton, A. V. Baranov, A. V. Fedorov, and Y. K. Gun'Ko. 2017. "Colloidal quantum dots for optoelectronics." Journal of Materials Chemistry $A, \mathbf{5}(26)$ : 13252-13275.

7. Sze, S.M. and Kwok, K. Ng. 2007. " Physics of Semiconductor Devices", $3^{\text {rd }}$ ed, John Wiley and Sons, New York.

8. Zubair, P.C. Ooi, K.C. and Sayyad, M.H. 2011. "Electrical characteristics of poly(methylsilsesquioxane) thin films for non-volatile memory", Solid State Communications, 151: 297-300.

9. Zubair A. and Muhammad H. 2009. "Extraction of electronic parameters of Schottky diode based on an organic semiconductor methyl-red", Physica E, 41: 631-634.

10. Thierry G., Vera M. and Christian S. 2007. "On the Shockley-Read-Hall modelgeneration recombination in semiconductors", Society for Industrial and Applied Mathematics, 67(4): 11831201.

11. Ijaz H., Nargis B., Sajjad H., Yousuf S., Omer N. and Magnus W. 2011. "Study of the Distribution of Radiative Defects and Reabsorption of the UV in ZnO Nanorods-Organic Hybrid White Light Emitting Diodes (LEDs)", Materials, 4: 1260-1270.

12. Kohei Y., Yoshinobu E., Motoi U., Atsunobu M., Hiroyuki I. and Masafumi M. 2019. "Fluorescence characterization of heavily $\mathrm{Eu}^{3+}$-doped lanthanum gallate glass spheres with high quenching concentration" Opt. Lett. 44(4): 875-878.

13. Omar A. 2017. "White Light Generation " LAP LAMBERT Academic publishing .

14. Lei Q., Ying Z., Kaushik R. Choudhury, Debasis Bera, Franky So, Jiangeng Xue, Paul H. Holloway, 2010. "Electroluminescence from light-emitting polymer/ZnO nanoparticle heterojunctions at sub-bandgap voltages", Nano Today, 5: 384-389.

15. Oleksii K. 2013. "Hybrid Light-Emitting Diode Enhanced With Emissive Nanocrystals", thesis, Department of Photonics Engineering - Technical University of Denmark in Denmark. 